\author{
INEEL/CON-01-00581 \\ PREPRINT
}

\title{
Air Ingress Analyses On A High Temperature Gas-Cooled Reactor
}

\author{
Chang H. Oh \\ Richard L. Moore \\ Brad J. Merrill \\ David A. Petti
}

November 11, 2001

2001 ASME International Mechanical
Engineering Congress and Exposition

This is a preprint of a paper intended for publication in a journal or proceedings. Since changes may be made before publication, this preprint should not be cited or reproduced without permission of the author.

This document was prepared as an account of work sponsored by an agency of the United States Government. Neither the United States Government nor any agency thereof, or any of their employees, makes any warranty, expressed or implied, or assumes any legal liability or responsibility for any third party's use, or the results of such use, of any information, apparatus, product or process disclosed in this report, or represents that its use by such third party would not infringe privately owned rights. The views expressed in this paper are not necessarily those of the U.S. Government or the sponsoring agency. 
IMECE2001/

\section{AIR INGRESS ANALYSES ON A HIGH TEMPERATURE GAS-COOLED REACTOR}

\author{
Chang H. Oh \\ Idaho National Engineering and Environmental \\ Laboratory, PO. Box 1625 \\ Idaho Falls, ID 83415 \\ Brad J. Merrill \\ Idaho National Engineering and Environmental \\ Laboratory, P.O. Box 1625 \\ Idaho Falls, ID 83415
}

\author{
Richard L. Moore \\ Idaho National Engineering and Environmental \\ Laboratory, P.O. Box 1625 \\ Idaho Falls, ID 83415 \\ David A. Petti \\ Idaho National Engineering and Environmental \\ Laboratory, P.O. Box 1625 \\ Idaho Falls, ID 83415
}

\begin{abstract}
A primary-pipe break accident is one of the design-basis accidents of a high-temperature gas-cooled reactor (HTGR). When this accident occurs, air is anticipated to enter the reactor core from the break and oxidize the in-core graphite structure in the modular pebble bed reactor (MPBR). This paper presents the results of the graphite oxidation model developed as part of the Idaho National Engineering and Environmental Laboratory's Direct Research and Development effort.
\end{abstract}

Although gas reactors have been tried in the past with limited success, the innovations of modularity and integrated state-ofart control systems coupled with improved fuel design and a pebble bed core make this design potentially very attractive from an economic and technical perspective. A schematic diagram on a reference design of the MPBR has been established on a major component level (INEEL \& MIT, 1999). Steady-state and transient thermal hydraulics models will be produced with key parameters established for these conditions at all major components. Development of an integrated plant model to allow for transient analysis on a more sophisticated level is now being developed. In this paper, preliminary results of the hypothetical air ingress are presented. A graphite oxidation model was developed to determine temperature and the control mechanism in the spherical graphite geometry.

\section{INTRODUCTION}

The high temperature gas-cooled reactor (HTGR) provides an alternative approach to the commercialization of nuclear power as compared to other fission-power-producing systems such as light water reactors (LWRs), heavy water reactors (HWRs), liquid metal-cooled fast breeder reactors (LMFBRs), and pressurized water reactors (PWRs). Gas cooling for nuclear reactors had been considered in the United States. In 1943 the first air-cooled reactor was built at Oak Ridge National Laboratory for the purpose of prototyping the production of plutonium and its extraction from the spent fuel prior to the operation of the major plutonium production plants built at Hanford, Washington. After the end of World War II, one more U.S. graphite-moderated, gas-cooled reactor was built at Brookhaven National Laboratory for general research related to the effects of irradiation, neutron science, and isotope separation (Wichner and Ball, 1999). In the mid-1950s, interest in gas cooling was revived in the U.S., United Kingdom, France and Germany. Several of these reactors were built. Recently, countries including U.S., South Africa, and the Netherlands (Verkerk, 1998a, 1998b) renewed their interest in the gascooled reactors, particularly modular pebble bed reactor concept.

\section{PROBLEM STATEMENT}

When the pebbles composed mainly of graphite are surrounded by air resulting from a hypothetical air ingress event, there is a need to determine the maximum pebble temperature from a reactor safety point of view to make certain the temperature produced by the oxidation of the pebble is within the maximum allowable limit.

From the literature (O'Brien et. al., 1988), the control mechanisms of oxidation are well defined as shown in Figure 1. 
At low temperatures (Regime 1), the reaction rate is controlled by chemical kinetics of oxygen reacting with active sites within the graphite. Mass transport rates are by diffusion, and nearly uniform oxidation occurs throughout the graphite mass. The percentages of sites within graphites that are reactive are very low and graphites are in general quite porous. Oxygen, or the oxidizing gas, will have the opportunity to diffuse sufficient distances into the material. Oxidation rates can therefore be expressed as a bulk rate based upon mass of the graphite, e.g., oxidized mass/(total mass-unit time). As temperature is increased, Regime 2 is reached where more sites within the graphite become active.

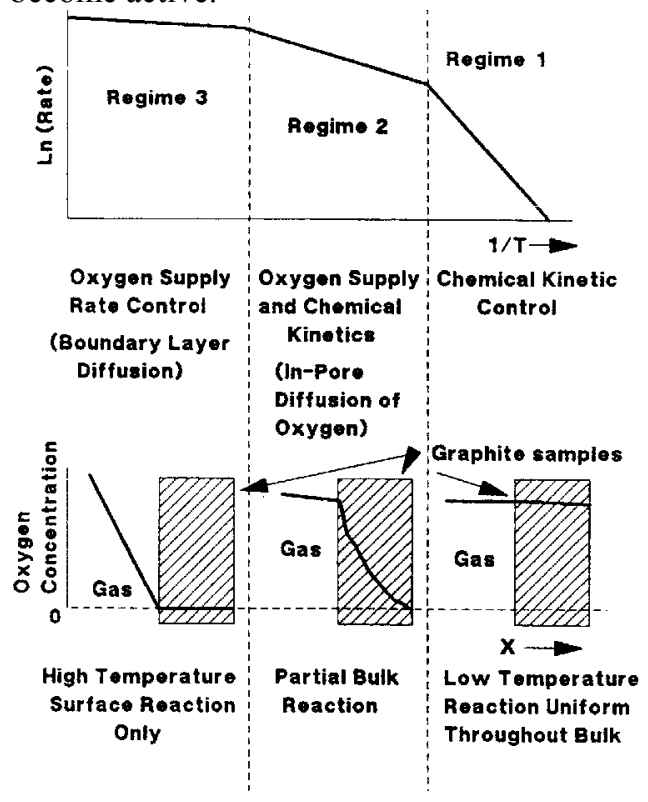

Figure 1. Schematic display of oxidation regimes.

Oxygen diffusing within the pores of the graphite is consumed at near-surface locations in the graphite. Both chemical reactivity and in-pore diffusion control the overall rate. Oxygen supply through boundary layer controls the reaction in Regime3. For bulk graphites, this occurs at temperatures greater than $1270 \mathrm{~K}$. Reaction with the graphite occurs at the outer surface of the graphite and rates are therefore expressed based on surface area in terms of $\mathrm{g} /\left(\mathrm{cm}^{2}-\mathrm{s}\right)$.

\section{Governing equation and boundary conditions}

For this study, the energy equation was solved using spherical geometry with boundary conditions specified below:

1. Air flows around the spherical graphite. The oxygen in the air reacts with the graphite surface to produce $\mathrm{CO}_{2}$ gas.

$\mathrm{C}+\mathrm{O}_{2} \rightarrow \mathrm{CO}_{2}, \Delta \mathrm{H}_{\mathrm{CO}_{2}}=-393.5 \mathrm{~kJ} / \mathrm{mol}$
2. The heat transfer at the interface between the graphite and the bulk stream is defined by Nusselt number.

$$
\mathrm{Nu}=\frac{\mathrm{h}_{\mathrm{c}} \cdot \mathrm{d}_{\mathrm{s}}}{\mathrm{k}}
$$

where $h_{c}$ is the convective heat transfer coefficient, $d_{s}$ is the sphere diameter, and $\mathrm{k}$ is the air thermal conductivity. The heat transfer coefficients are difined in the following section.

3. The diffusive mass transfer rate through the boundary layer is defined by the Sherwood number.

$$
\mathrm{S}_{\mathrm{h}}=\mathrm{Nu}\left(\frac{\mathrm{Sc}}{\mathrm{Pr}}\right)^{1 / 3}=\frac{\mathrm{k}_{\mathrm{mi}} \mathrm{L}}{\mathrm{D}_{\mathrm{ab}}}
$$

where $\mathrm{k}_{\mathrm{mi}}$ is the convective mass transfer coefficient, $\mathrm{D}_{\mathrm{ab}}$ is the binary diffusion coefficient and $\mathrm{L}$ is the characteristic length.

$$
\mathrm{k}_{\mathrm{mi}}=\frac{\mathrm{D}_{\mathrm{ab}}}{\mathrm{L}} \mathrm{Nu}\left(\frac{\mathrm{Sc}}{\mathrm{Pr}}\right)^{1 / 3}
$$

Given the mass transfer coefficients, the oxygen mass flux arriving at the pebble surface is

$$
\Gamma=\left(\frac{12}{32}\right) \cdot \rho \cdot \mathrm{k}_{\mathrm{mi}}
$$

where $\rho$ is the oxygen density.

These mass transfer equations are used to compare with the kinetic rate, which is described in later sections.

The above diffusion coefficient was calculated using the following equation.

$$
\begin{aligned}
& \mathrm{D}_{\mathrm{ab}}=\frac{0.00143 \mathrm{~T}^{1.75}}{\mathrm{P} \cdot \mathrm{M}_{\mathrm{ab}}^{1 / 2} \cdot\left[\left(\sum_{\mathrm{v}}\right)_{\mathrm{a}}^{1 / 3}+\left(\sum_{\mathrm{v}}\right)_{\mathrm{b}}^{1 / 3}\right]^{2}} \\
& \mathrm{M}_{\mathrm{ab}}=2 \cdot\left[\left(\frac{1}{\mathrm{M}_{\mathrm{a}}}\right)+\left(\frac{1}{\mathrm{M}_{\mathrm{b}}}\right)\right]^{-1}
\end{aligned}
$$

where $\mathrm{M}_{\mathrm{a}}$ and $\mathrm{M}_{\mathrm{b}}$ are the molecular weights for air and $\mathrm{CO}_{2}$, respectively, and $\sum_{\mathrm{v}}$ is diffusion volume (19.7 for air, and 26.9 for $\mathrm{CO}_{2}$, Reid, Praunitz, and Poling (1987)).

The oxidation rate is determined as the minimum value of three values calculated each time step which are:

(1) graphite oxidation rate by kinetics, (2) oxygen mass flux in the bulk stream, (3) oxygen mass flux arriving at the interface.

The equation solved for oxidation of the spherical pebble is the partial differential equation (PDE) shown below:

$\rho_{p} c_{p} \frac{\partial T}{\partial t}+\rho \frac{1}{r^{2}} \frac{\partial}{\partial r}\left(r^{2} v_{r} T c_{p}\right)=\frac{1}{r^{2}} \frac{\partial}{\partial r} k r^{2} \frac{\partial T}{\partial r}+\dot{q}+q_{\text {decay }}$ 
where $\rho_{p}$ is the density of graphite pebble, $\mathrm{c}_{\mathrm{p}}$ is the specific heat, $\mathrm{T}$ is the temperature, $\mathrm{t}$ is the time, $\mathrm{r}$ is the radius, $\mathrm{V}_{\mathrm{r}}$ is a node advection velocity defined as the oxidation rate divided by density of graphite, $\mathrm{k}$ is the thermal conductivity, $\mathrm{q}_{\text {decay }}$ is the decay heat, and $\dot{\mathrm{q}}$ is the net surface heat flux and is defined as

$\dot{\mathrm{q}}=\mathrm{q}_{\mathrm{ox}}-\mathrm{h}_{\mathrm{c}} \cdot \Delta \mathrm{T}$

where $\mathrm{q}_{\mathrm{ox}}$ is the heat flux due to the oxidation and $\mathrm{h}_{\mathrm{c}}$ is the convective heat transfer coefficient calculated from the Nusselt (Eqn 1).

The decay heat used in these calculations is listed below: if time $\leq 1.45$ seconds, decay heat $=800 \mathrm{~W} /$ volume. if $1.45<$ time $\leq 25$ seconds, decay heat $=$ $800 \mathrm{~W} /$ volume* $1.394 \exp (-0.26 *$ time $)+0.046$

if $25<$ time $\leq 1,000$ seconds, decay heat $=$ $800 \mathrm{~W} /$ volume* $(0.0495-2.0518 \mathrm{e}-5 *$ time $)$

if time $>1000$, decay heat $=800 \mathrm{~W} /$ volume* 0.03 .

The decay heat is small when compared to the heat of formation for $\mathrm{CO}_{2}$. The decay heat is about $50 \mathrm{~W}\left(4420 \mathrm{~J} / \mathrm{m}^{2}\right.$-sec $)$ after 17 seconds which is much smaller than the heat obtained from oxidation, provided sufficient oxygen is available at $1000 \mathrm{~K}$.

The above equation (7) is integrated:

$$
\begin{aligned}
\int_{V_{i}}\left(4 \pi r^{2} d r\right) p c_{p} \frac{\partial T}{\partial t} & +\int_{V_{i}} 4 \pi r^{2} d r \frac{\rho}{r^{2}} \frac{\partial}{\partial r}\left(r^{2} v_{r} T c_{p}\right)=\int_{V_{i}} 4 \pi r^{2} d r\left(\frac{1}{r^{2}}\right) \frac{\partial}{\partial r} k r^{2} \frac{\partial T}{\partial r} \\
& +\int_{V_{i}} 4 \pi r^{2} d r \cdot \dot{q}+\int_{V_{i}} 4 \pi r^{2} d r \cdot q_{\text {decay }}
\end{aligned}
$$

In the control volumes i, $\rho, \mathrm{c}_{\mathrm{p}}, \mathrm{k}$ and $\mathrm{q}$ are assumed to be constants.

The PDE was rewritten in a finite difference form as:

$$
\begin{aligned}
& \frac{\rho c_{p i}}{3 \Delta t}\left(r_{j+1}^{3}-r_{j}^{3}\right)\left(T_{i}^{n+1}-T_{i}^{n}\right)+ \\
& \rho c_{p_{i}} v_{r}\left[r_{j+1}^{2} \cdot c_{p_{i}} T_{i}^{n+1}-r_{j}^{2} \cdot c_{p_{i-1}} T_{i-1}^{n+1}\right]= \\
& \frac{k_{j+1} r_{j+1}^{2}}{r_{i+1}-r_{i}}\left[T_{i+1}^{n+1}-T_{i}^{n+1}\right]-\frac{k_{j} r_{j}^{2}}{r_{i}-r_{i-1}}\left(T_{i}^{n+1}-T_{i-1}^{n+1}\right)+ \\
& \frac{\dot{q}}{3}\left(r_{j+1}^{3}-r_{j}^{3}\right)+\frac{q_{d e c a y}}{3}\left(r_{j+1}^{3}-r_{j}^{3}\right)
\end{aligned}
$$

Depending upon the oxidation regimes, oxidation rates were selected for this study.

For Regime 1 in Figure 1, Grsac model (Wichner and Ball, 1999) was used:

$$
\begin{aligned}
\text { Rate }= & \left\{2.04 \mathrm{e} 7[1+1.37 * \mathrm{AGE} * \mathrm{PR}] * \exp \left(\frac{-45000}{\mathrm{R} * \mathrm{~T}}\right) \mathrm{Po}_{2}{ }^{0.7}+1.64 \mathrm{e} 6 * \exp \left(\frac{-24800}{\mathrm{R} * \mathrm{~T}}\right)\right. \\
& \left.*\left(\frac{\mathrm{Po}_{2}}{0.21}\right)^{0.86} * \mathrm{AGE}^{*} \mathrm{PR}\right\} *\left[9.368 \mathrm{e}-2 * \mathrm{~T}^{2}-0.02859 * \mathrm{~T}+22.688\right] * \frac{\rho}{\mathrm{MW}}
\end{aligned}
$$

where AGE is a reactor age factor, $\mathrm{PR}$ is a local to average core power, $\mathrm{R}$ is the universal gas constant, $\mathrm{Po}_{2}$ is the partial oxygen pressure, $\mathrm{T}$ is temperature, $\rho$ is the density of the graphite, and MW is the molecular weight of the graphite. A value of unity was used for ACE and PR. The transition temperature depends upon impurities in the graphite or reacting gas, microstructure of the graphite, and the type and concentration of the reacting gas (Veet al. 1978, Bunnell et al., and 1987. Gulbransen et al., 1964, Helms and MacPherson, 1965). The transition temperature between Regime 1 and Regime 2 is $395 \mathrm{~K}$ as shown in Figure 2.

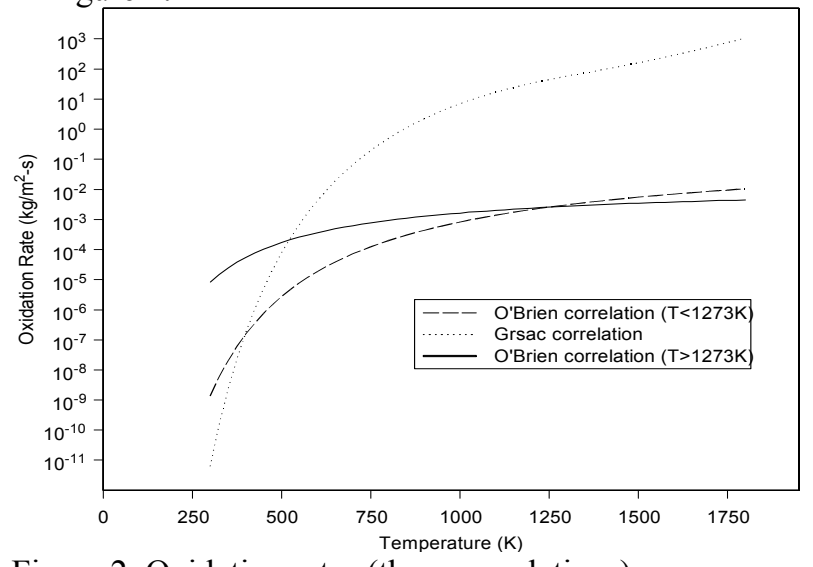

Figure 2. Oxidation rates (three correlations).

For Regime 2 and 3, INEEL's correlations (O'Brien et al., 1988) are used. The type and dimension of the graphite specimen used for these correlations are as follows: Union carbide (density of $1720 \mathrm{~kg} / \mathrm{m}^{3}$ ), Pfizer pyroltic (density of $\left.2150 \mathrm{~kg} / \mathrm{m}^{3}\right)$, cylindrical specimens $2.7 \mathrm{~cm}$ in diameter and 1.27 $\mathrm{cm}$ in height, and $12.4279 \mathrm{~g}$-mass.

For $\mathrm{T}<1273 \mathrm{~K}$,

Rate $=16 \exp \left(\frac{-5710}{\mathrm{~T}}\right) \cdot(\mathrm{g} / \mathrm{min})=0.2475 \exp \left(\frac{-5710}{\mathrm{~T}}\right) \cdot\left(\mathrm{kg} / \mathrm{m}^{2} \cdot \mathrm{sec}.\right)$

For $1273<\mathrm{T}<2073 \mathrm{~K}$, 
Rate $=1.01 \exp \left(\frac{-2260}{\mathrm{~T}}\right) \cdot(\mathrm{g} / \mathrm{min})=0.0156 \exp \left(\frac{-2260}{\mathrm{~T}}\right) \cdot\left(\mathrm{kg} / \mathrm{m}^{2} \cdot \mathrm{sec}.\right)$

Those oxidation correlations (Eqns. (11), (12), and (13)) used in these calculations are based on oxygen content at standard atmospheric conditions. As a first or order approximation, the oxidation rate is assumed to vary linearly with the oxygen partial pressure as shown below:

Oxidation rate $=\frac{P_{o x}}{0.21 e 5} \cdot$ Rate $($ Eqns $.12,13$, or 14$)$

The following equation was used for the heat of formation for $\mathrm{CO}_{2}$ :

$\Delta H_{f_{\mathrm{CO} 2}}=\left(\frac{4187}{44}\right) \cdot\left(-93690 .-1.63 \cdot T / 2.303+0.00007 \cdot T^{2}-460000 / T\right)$

Oxidation heat $=\left(\frac{44}{12}\right) \cdot \Delta H_{f_{\mathrm{CO} 2}} \cdot$ lowest value (kinetics,

$\mathrm{O}_{2}$ mass flux in bulk, $\mathrm{O}_{2}$ mass flux at the surface) (16)

Other inputs to the computer program are:

diameter of the graphite $=60 \mathrm{~mm}$

bulk temperature $=1100 \mathrm{~K}$

Nusselt number $=10,40$, and 90

oxygen partial pressure $=0.00447 \mathrm{MPa}, 0.0106 \mathrm{MPa}$, and

$0.01704 \mathrm{MPa}$.

thermal conductivity of air at the bulk temperature $=0.06 \mathrm{~W} / \mathrm{m}$ -

K

density of air at the bulk temperature $=0.31 \mathrm{~kg} / \mathrm{m}^{3}$

viscosity of air at the bulk temperature $=1120 \mathrm{~N}-\mathrm{s} / \mathrm{m}^{2}$

The thermal conductivity and heat capacity of graphite (based on GraphNOL N3M, Mattas, 1988) are calculated using the following equations:

$k(W / m \cdot K)=30 .+251 . \exp \left(-1.632 * 10^{-3} * T\right)$
$c_{p}(J / k g \cdot K)=2000 .-2204 . \exp \left(-2.028 * 10^{-3} * T\right)$

Figure 3 shows the complete oxidation regimes with transitions between the regimes.

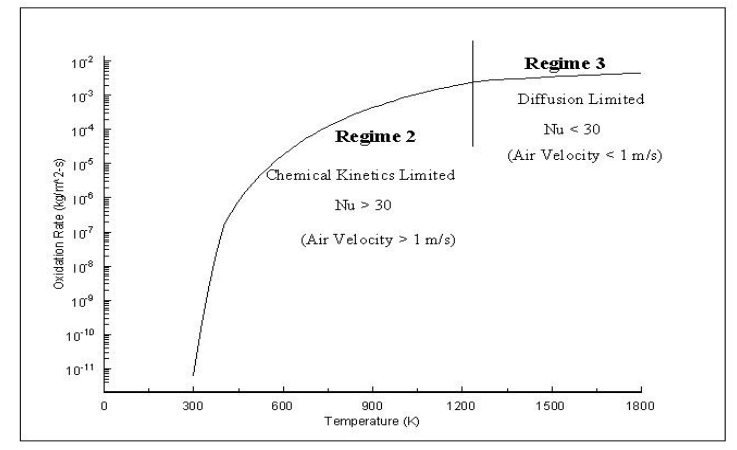

Figure 3. Kinetics regime map depending $\mathrm{n}$ temperature.

\section{$\underline{\text { Heat transfer correlations }}$}

The convective heat transfer is very important in these calculations. The heat transfer coefficient, $h_{c}$, between the surface of a sphere and a fluid through which it is moving with relative velocity, is given by Ranz and Marshall (1952)

$$
\begin{aligned}
& \mathrm{h}_{\mathrm{c}}=\frac{\mathrm{k}}{\mathrm{d}_{\mathrm{s}}}\left(2+0.6 * \operatorname{Pr}^{1 / 3} * \operatorname{Re}^{1 / 2}\right) \\
& \mathrm{Nu}=\frac{\mathrm{h}_{\mathrm{c}} \cdot \mathrm{d}_{\mathrm{s}}}{\mathrm{k}}
\end{aligned}
$$

where $\mathrm{k}, \mathrm{d}_{\mathrm{s}}, \operatorname{Pr}$, and Re are the thermal conductivity, diameter of the sphere, Prandtl and Reynolds number of the fluid.

The heat transfer in fixed beds of coarse solids may be approximated by Ranz and Marshall (1952):

$$
\begin{gathered}
\mathrm{h}_{\mathrm{c}}=\frac{\mathrm{k}}{\mathrm{d}_{\mathrm{s}}}\left(2+1.8 * \operatorname{Pr}^{1 / 3} * \mathrm{Re}^{1 / 2}\right) \text { or } \\
\mathrm{Nu}=\frac{\mathrm{h}_{\mathrm{c}} \cdot \mathrm{d}_{\mathrm{s}}}{\mathrm{k}}
\end{gathered}
$$

A similar heat transfer correlation developed for a pebble sphere is found by Kunii and Levenspiel (1962) such as

$$
\begin{aligned}
& \mathrm{h}_{\mathrm{c}}=0.664 * \frac{\mathrm{k}}{\mathrm{d}_{\mathrm{s}}} *\left(\frac{\mathrm{Re}}{\varepsilon}\right)^{1 / 2} * \operatorname{Pr}^{1 / 3} \text { or } \\
& \mathrm{Nu}=\frac{\mathrm{h}_{\mathrm{c}} \cdot \mathrm{d}_{\mathrm{s}}}{\mathrm{k}}
\end{aligned}
$$

where $\varepsilon$ is the void fraction of the pebble bed reactor.

Based upon experimental data from several independent studies of heat convection in pebble beds (Waermeuebergang 1978), heat transfer can be determined by 


$$
\begin{aligned}
\mathrm{h}_{\mathrm{c}}= & \frac{\mathrm{k}}{\mathrm{d}_{\mathrm{s}}}\left(\frac{\operatorname{Pr}^{0.333}}{\varepsilon^{1.18}} \mathrm{Re}^{0.36}+0.033 \frac{\operatorname{Pr}^{0.5}}{\varepsilon^{1.07}} \mathrm{Re}^{0.86}\right) \\
& \text { or } \mathrm{Nu}=\frac{\mathrm{h}_{\mathrm{c}} \cdot \mathrm{d}_{\mathrm{s}}}{\mathrm{k}}
\end{aligned}
$$

Eqn (20) was used for heat transfer coefficient calculations because the criteria of Eqn (20) such as $\operatorname{Re}>100$ is closer to our applications.

Figure 4 shows heat transfer coefficients using the aforementioned four different heat transfer correlations.

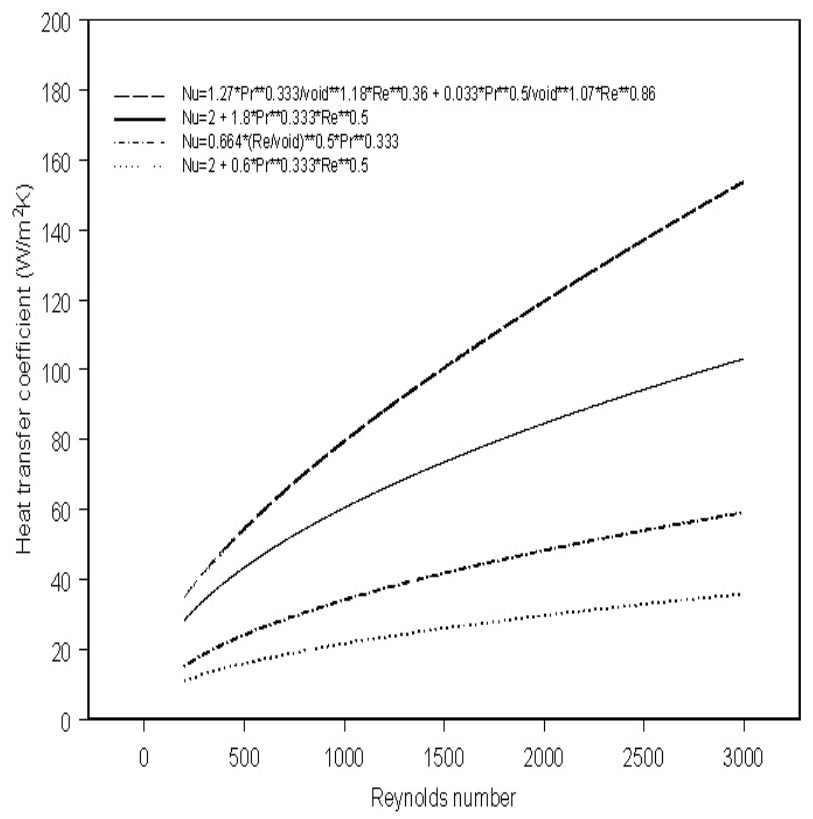

Figure 4. Heat transfer vs. Reynolds number using correlations developed for spheres in a fixed bed.

To calculate the Reynolds number, the air velocity was estimated by using the following equation developed by Takase et. al (1996):

$$
\mathrm{U}_{\text {air }}(\mathrm{t})=\frac{\mathrm{V}}{\mathrm{A}_{\mathrm{N}}}\left[\frac{1}{\mathrm{x}_{\text {air }}(\mathrm{t})} * \frac{\mathrm{dx}_{\text {air }}(\mathrm{t})}{\mathrm{dt}}\right]
$$

where $\mathrm{V}, \mathrm{A}_{\mathrm{N}}$, and $\mathrm{X}_{\text {air }}$ are the volume and cross-sectional area of the bed and the mole fraction of air. Using the geometry of the bed, Figure 7 in the Takase's paper $(\mathrm{dx} / \mathrm{dt}=$ slope of the mole fraction curve at a specified time), a Reynolds number was calculated at about 292 (air velocity $0.65 \mathrm{~m} / \mathrm{s}$ using Eqn. 23) which gives the heat transfer coefficient of $12 \mathrm{~W} / \mathrm{m}^{2}-\mathrm{K}$ using the above equation (20). However, the geometry and breach location of the Takasa experiment is very different compared with the pebble bed reactor. The location of the breach greatly influences air mass flow to the reactor. As preliminary analyses are now showing, breaks at the core inlet show very low convective flows compared to calculated values using Eqn (23). Therefore, our analyses are very conservative.

The partial pressure of oxygen is also important in these calculations. Air consists of $21 \%$ oxygen by volume.

$$
\begin{aligned}
& \mathrm{V}_{\mathrm{g}}=\varepsilon \cdot \mathrm{V} \\
& \mathrm{P}_{\text {total }}=\mathrm{P}_{\text {air }}+\mathrm{P}_{\text {helium }} \\
& \rho_{\text {air }}=\frac{\left(\mathrm{P}_{\text {total }}-\mathrm{P}_{\text {helium }}\right)}{\mathrm{R}_{\text {air }} \cdot \mathrm{T}}=\frac{\mathrm{M}_{\text {air }}}{\mathrm{V}_{\mathrm{g}}}=\frac{\text { mass of air }}{\text { total gas volume }}
\end{aligned}
$$

According to Amagat's law, partial volume occupied by each gas based upon $\mathrm{P}_{\text {total }}$ and $\mathrm{T}$.

$$
\begin{aligned}
& \mathrm{V}_{\mathrm{g}}=\mathrm{V}_{\text {air }}+\mathrm{V}_{\text {helium }} \text { at } \mathrm{P}_{\text {total }} \text { and } \mathrm{T} . \\
& \mathrm{P}_{\text {total }}=\frac{\mathrm{M}_{\text {air }}}{\mathrm{V}_{\text {air }}} \mathrm{R}_{\text {air }} \cdot \mathrm{T}
\end{aligned}
$$

Combing these equations, the partial oxygen pressure is:

$$
P_{\mathrm{O}_{2}}=0.21 *\left(P_{\text {total }}-P_{\text {helium }}\right)
$$

\section{RESULTS}

To validate the model, numerical results obtained from solving the above PDE equation were compared with the following analytical solutions using the following equation (Carslaw and Jaeger,1959):

$$
\begin{aligned}
& \mathrm{T}=\frac{\mathrm{aT}_{\mathrm{o}}}{\mathrm{r}}\left\{\operatorname{erfc} \frac{(2 \mathrm{n}+1) \mathrm{a}-\mathrm{r}}{2(\kappa \mathrm{t})^{1 / 2}}-\operatorname{erfc} \frac{(2 \mathrm{n}+1) \mathrm{a}+\mathrm{r}}{2(\kappa \mathrm{t})^{1 / 2}}\right\} \\
& \text { where } \kappa=\frac{\mathrm{k}}{\mathrm{c}_{\mathrm{p}} \cdot \rho}, \mathrm{T}_{\mathrm{o}} \text { is the }
\end{aligned}
$$

surface temperature. In this comparison, $\dot{q}$ and $q_{\text {decay }}$ in Eqn

(7) were set to zero.

Figure 5 shows the comparison between analytical solutions and numerical solutions at various radii and time. For these comparison calculations, the initial temperature in the graphite 
was set to zero with a surface temperature of $1270 \mathrm{~K}$, thermal conductivity of $36 \mathrm{~W} / \mathrm{m}-\mathrm{K}$, heat capacity of $1465 \mathrm{~J} / \mathrm{kg}-\mathrm{K}$, density of $900 \mathrm{~kg} / \mathrm{m}^{3}$, and diameter of $10 \mathrm{~mm}$. Oxidation in the program was turned off just to calculate the heat conduction without oxidation. The results agree fairly well as shown in Figure 5.

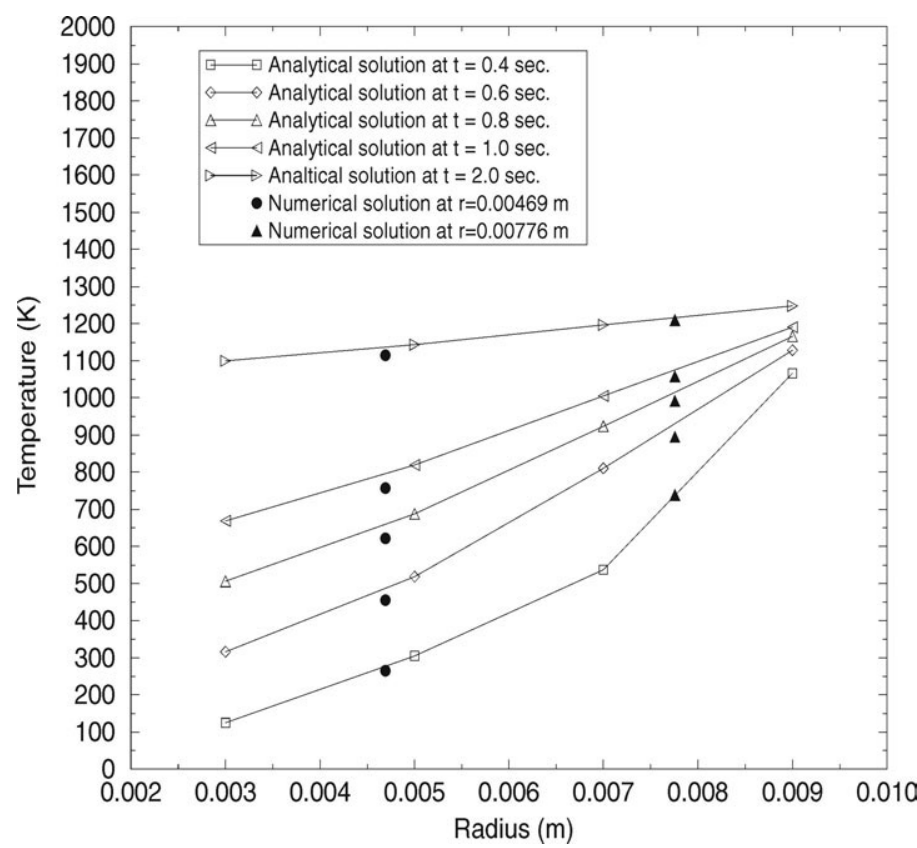

Figure 5. Comparison of Analytical Solutions with Numerical Ones.

Using Eqn. (20), Nusselt numbers were calculated. Two oxygen partial pressures were assumed: a partial oxygen pressure of 0.0106 MPA was based on 0.5 mole fraction of air and 0.5 mole fraction of helium in the gas stream, and a partial oxygen pressure of $0.00447 \mathrm{MPa}$ based on 0.2 mole fraction of air and 0.8 mole fraction of helium using Eqn (29).

As shown in Figure 6, as the oxygen partial pressure increases, the graphite temperature increases. Using the same pressures, Nusselt numbers were changed to determine the effect of the Nusselt number on temperature.

As shown in Figure 7, temperature increases as Nusselt number is reduced as anticipated. The effect of pressure has the same trend as those of Figure 6.

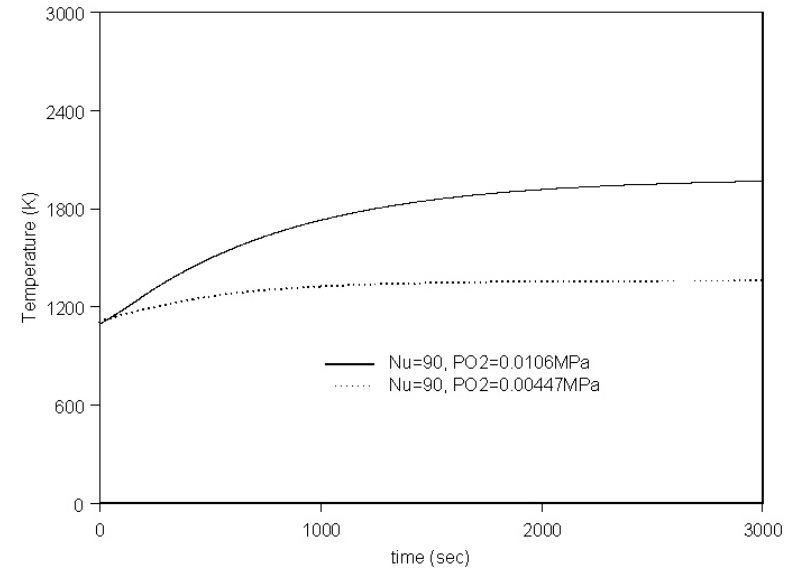

Figure 6. Effect of oxygen partial pressure on temperature for $\mathrm{Nu}=90$.

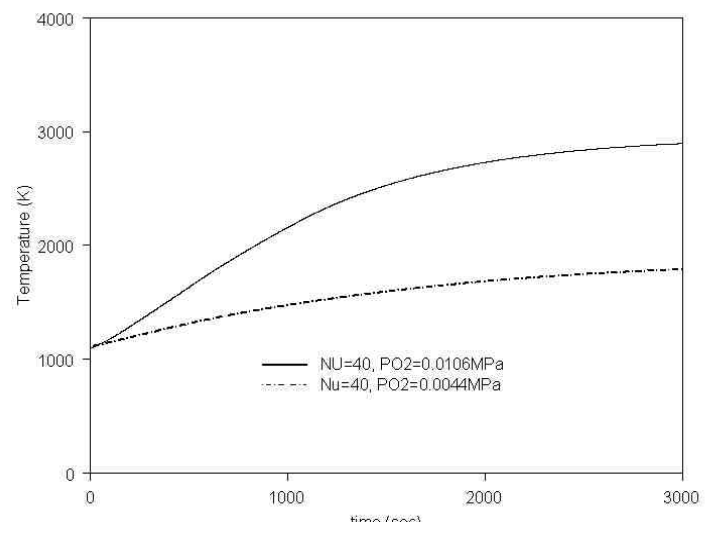

Figure 7. Effect of the oxygen pressure on temperatures for $\mathrm{Nu}=40$.

Calculations were made to determine whether the oxidation was either "diffusion-limited" or "kinetics-limited". For the "diffusion-limited", mass transfer equation (4) is used to calculate the oxygen mass flux arriving at the interface between the graphite surface and bulk stream. An Arrhenius expression (Eqns. (11), (12) and (13)) was used for "kinetics-limited". Then the values calculated from "diffusion-limited" and "kinetics-limited" are compared, and the smaller values are taken for the reaction rate (Figure 8). 


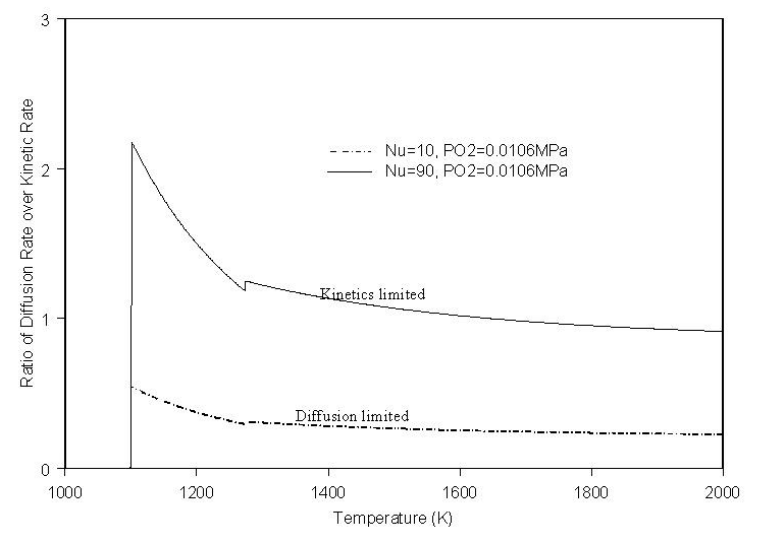

Figure 8. Kinetics-limited vs. diffusion-limited.

A case with Nusselt number of 10 and the partial oxygen pressure of $0.0106 \mathrm{MPa}$ is "diffusion-limited" while a case with Nusselt number of 90, and the partial oxygen pressure of $0.0106 \mathrm{Mpa}$ is "kinetic-limited". The small Nusselt number makes the mass transfer rate obtained in Eqn (3) smaller, which results in "diffusion-limited". This means that the diffusion controls the oxidation mechanism. If it is "kinetics-limited, " the temperature profile is affected by the inversed $\mathrm{T}$ in the exponent function (Eqns. (11), (12), and (13)), which makes the steady state value as shown in Figure 9.

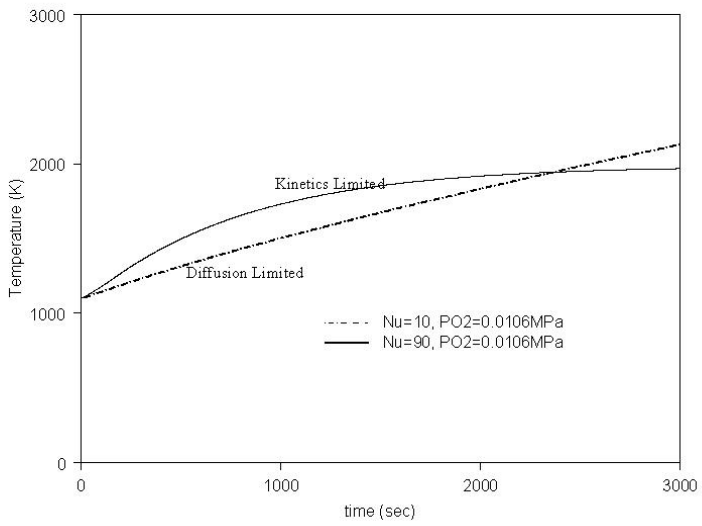

Figure 9. Temperature profile of Figure 9 depending on the control mechanism.

To determine the effect of decay heat for the graphite temperature profile shown in Figure 10, the ratio of oxidation heat over the decay heat was calculated as shown in Figure 10. In Figure 10, the exothermic heat due to the oxidation is much greater than decay heats, provided sufficient oxygen is supplied.

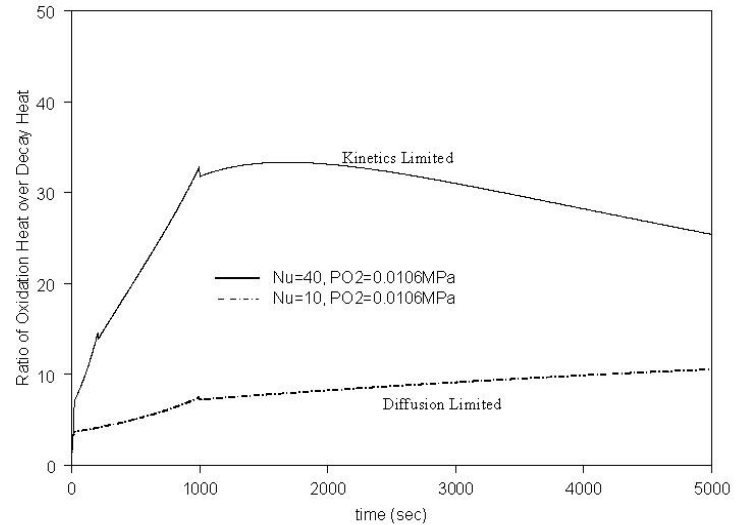

Figure 10. Ratio of heat due to oxidation to decay heat for Figure 8.

\section{CONCLUSIONS AND RECOMMENDATIONS FOR FUTURE STUDIES}

Heat transfer, mass transfer, and oxygen pressures are important parameters for this study.

The Nusselt number depends on thermal conductivity of the air and air velocity over the graphite. As anticipated, a lower Nusselt number results in higher temperatures in the graphite due to the reduced heat transfer at the surface. The partial pressure of oxygen affects the temperature significantly. Once the oxygen mass flow introduced to the reactor by a hypothetical pipe break accident is determined by RELAP5/ATHENA (ATHENA, 2000) or MELCOR (Summers et al, 1991) calculations, the detailed graphite temperature calculations can be made using the oxidation model developed in this study. Parametric study can be performed using this model.

Mike O'Brien's experiments and correlations are based upon an annular geometry that has different surface-to-volume ratio with different heat transfer, mass transfer, and boundary layer thickness as opposed to those for graphite pebbles. Depending on the type of graphite used for their studies shown in the literature, oxidation rates and thermal properties are reported different along with the surface-to-volume ratio. Further studies are recommended for the accurate oxidation rate and thermal properties for the type of graphite with the specific surface-tovolume ratio to be selected for the reactor.

Based on the preliminary results obtained in this paper, we conclude that the computer model developed for this study performs as well as anticipated. Once we know accurate thermal properties of graphite and oxidation kinetic rates, it can be a very useful tool to utilize this model for the detailed study. 


\section{ACKNOWLEDGEMENTS}

This work was performed under the auspices of the U.S. Department of Energy under the DOE Operations Office Contract No. DE-AC0799ID13727.

\section{REFERENCES}

1. Bunnell, L.R. et al., "Oxidation of TSX Graphite Over the Temperature Range 450 to 1C," UNI-SA-207, PNL-SA-14925, march 1987.

2. Carslaw, H.S. and J.C. Jaeger, Conduction of Heat in Solids, $2^{\text {nd }}$ Ed., Oxford Press, 1959.

3. Gulbransen, E.A. et al., "Ablation of Graphite in Oxygen and Air at $1000-1400^{\circ} \mathrm{C}$ Under Flow Conditions," Carbon, 1., 1964.

4. Helms, R.E., and R.E. MacPherson, "The Reaction of Steam with Large Specimen of Graphite for the Experimental GasCooled Reactor," ORNL-TM-984, March 1965.

5. Idaho National Engineering and Environmental Laboratory and Massachussets Institute of Technology, 1999, Strategic Nuclear Research Collaboration: FY-99 Annual Report, INEEL/EXT-99-00694, July, 1999.

6. Mattas, R.F., A letter report (ANL), December 22, 1988.

7. Kunni, D. O. Levenspiel, Fluidized Engineering, John Wiley \& Sons, 1962.

8. O'Brien, M.H., B.J. Merrill, and S.N. Ugaki, "Combustion Testing and Thermal

Modeling of Proposed CIT graphite Tile Materials," EGG-FSP8255, September 1988.

9. Ranz, W.E. and W.R. Marshall, Jr., Chem. Eng. Progr., 48, $141,1952$.

10. Reid, R.C. J.M. Praunitz, and B.E. Poling, The Properties of gases \& Liquids," $4^{\text {th }}$ Ed., McGraw-Hill,Inc., 1987.

11. Summers et al., MELCOR 1.8.0: A Computer Code for Severe Nuclear Reactor Accident Source Term and Risk Assesment Analyses, NUREG/CR-5532, Sandia National Laboratory Report, SAND-90-0364, January 1991.

12. Takase, K., T. Kunugi, and Y. Seki, "Effect of Breach Area and Length to Exchange Flow Rates Under the LOVA Condition in A Fusion Reactor," FUSION TECHNOLOGY, 30, December 1996.

13. The RELAP-3D Code development Team, ATHENA Code manual, Idaho National Engineering and Environmental

Laboratory, INEEL-EXT-98-00834, Revision 1.2a, May 2000.
14. Velasquez, C et al., "The Oxidation of H-451 Graphite by Steam, Part 1: Reaction Kinetics," GA-A14951, UC-77, August 1978.

15. Waermeuebergang im Kugelhaufen, KTA 3102.1 KTA, June 1978.

16. Wichner,R.P. and S.J. Ball, "Potential Damage to GasCooled Graphite reactors Due to Severe Accidents,"

ORNL/TM-13661, April 1999. 